\title{
The effects of meteorological factors on the occurrence of Ganoderma sp. spores in the air
}

\author{
Agnieszka Grinn-Gofroń • Agnieszka Strzelczak
}

Received: 14 September 2009 /Revised: 28 April 2010 /Accepted: 28 April 2010 / Published online: 29 May 2010

(C) The Author(s) 2010. This article is published with open access at Springerlink.com

\begin{abstract}
Ganoderma sp. is an airborne fungal spore type known to trigger respiratory allergy symptoms in sensitive patients. Aiming to reduce the risk for allergic individuals, we analysed fungal spore circulation in Szczecin, Poland, and its dependence on meteorological conditions. Statistical models for the airborne spore concentrations of Ganoderma $\mathrm{sp}$. - one of the most abundant fungal taxa in the areawere developed. Aerobiological sampling was conducted over 2004-2008 using a volumetric Lanzoni trap. Simultaneously, the following meteorological parameters were recorded: daily level of precipitation, maximum and average wind speed, relative humidity and maximum, minimum, average and dew point temperatures. These data were used as the explaining variables. Due to the nonlinearity and non-normality of the data set, the applied modelling techniques were artificial neural networks (ANN) and mutlivariate regression trees (MRT). The obtained classification and MRT models predicted threshold conditions above which Ganoderma sp. appeared in the air. It turned out that dew point temperature was the main factor influencing the presence or absence of Ganoderma sp. spores. Further analysis of spore seasons revealed that the airborne fungal spore concentration depended only slightly on meteorological factors.
\end{abstract}

A. Grinn-Gofroń $(\bowtie)$

Department of Plant Taxonomy and Phytogeography,

University of Szczecin,

Wąska 13,

71-415 Szczecin, Poland

e-mail: agofr@univ.szczecin.pl

\section{A. Strzelczak}

Institute of Chemistry and Environmental Protection,

Westpomeranian University of Technology,

Aleja Piastów 42,

71-065 Szczecin, Poland
Keywords Ganoderma sp. Artificial neural network · Multivariate regression tree $\cdot$ Meteorological parameter

\section{Introduction}

Fungal spores are an important component of bioaerosols, and are considered to act as indicators of the level of atmospheric bio-pollution. The general spectrum of spores present in the air is very broad, with basidiospores representing a significant percentage of air mycoflora.

Basidiomycota is the most morphologically complex fungal division, enclosing approximately 25,000 species and including many of the conspicuous larger fungi, such as mushrooms, bracket-fungi, puff-balls and earth-stars as well as plant pathogenic smuts and rusts (Hawksworth et al. 1983). Basidiospores can be dispersed over long distances by the wind and have been reported as an important component of the air spora in urban areas in many different parts of the world (Levetin 1990, 1991; Hasnain 1993; Li and Kendrick 1994).

The basisiospores of Ganoderma sp., commonly known as a bracket fungus or wood decay fungus, are an important and prevalent group of fungal airspora worldwide (Lehrer et al. 1994; Levetin 1990, 1991; Hasnain 1993; Halwagy 1994; Li and Kendrick 1995). At least six species of Ganoderma sp. occur in Poland. Their polyspores are found growing on dead or living hardwood and conifers. The spores are easily recognizable by their orange inner wall and spines that penetrate a colourless outer wall. Interwall connections and a prominent germ pore with truncated apex are also distinctive features. Ganoderma sp. spores range in size from 6.5 to $13 \times 5$ to $9 \mu \mathrm{m}$.

Gregory and Hirst (1952) first suggested that basidiospores might be associated with respiratory allergy. Studies 
from various parts of the world have clearly implicated Ganoderma sp. spores as aeroallergens (Tarlo et al. 1979; Hasnain et al. 2004). In various reports, $10-48 \%$ human sensitisation in skin prick tests has been attributed to Ganoderma sp. spores (Tarlo et al. 1979; Butcher et al. 1987; Singh et al. 1995). Even though Ganoderma sp. spores are known to be allergenic, and may be one of the principal causes of seasonal respiratory allergy, their number in the air and their seasonal periodicities have seldom been studied.

It is well known that weather conditions influence the day-to-day variability as well as seasonal levels of atmospheric spore concentrations. Through aerobiological analysis of Lanzoni slides, it appeared that Ganoderma sp. spores were more abundant during certain years; however, these spores were not always present during the whole period studied.

The results of this investigation were based on aerobiological monitoring performed in Szczecin in 2004-2008. Szczecin is situated in the Odra river valley in North-West Poland, $60 \mathrm{~m}$ a. s. $1 ., 53^{\circ} 26^{\prime} 26^{\prime \prime} \mathrm{N}, 14^{\circ} 32^{\prime} 50^{\prime \prime} \mathrm{E}$. The city is surrounded by forests, farmlands and abandoned farmland areas, which provide suitable media for spore production. The present, "Baltic" climate of Szczecin is created by the impact of the Atlantic component, and is characterised by mild winters and cool summers. The climate in Szczecin is temperate-warm with a clear influence of the sea. The driest months are February and March, the rainiest and hottest month is July, and the coolest is January. The mean annual precipitation is relatively low at $500 \mathrm{~mm}$, and the flora vegetation seasons lasts 210-220 days.

This study was undertaken to specifically determine the daily concentration of Ganoderma sp. spores over the 5year study period, and to examine the relationship between the atmospheric Ganoderma sp. spore content and the meteorological parameters in the area of Szczecin. Due to multivariaty, and the non-normality and non-linearity of the data set, we used novel data analysis techniques: artificial neural networks (ANN) and mutlivariate regression trees (MRT).

\section{Materials and methods}

Daily summed counts of airborne fungal spores were performed using a 7-day recording Lanzoni volumetric trap. The trap was installed on a rooftop in Szczecin city (district Śródmieście), at a height of $21 \mathrm{~m}$ above ground level ( $52 \mathrm{~m}$ above sea level). The urban structure is not very dense, with many green squares and parks. The measuring site was $0.5 \mathrm{~km}$ NW of Jan Kasprowicz Park, the largest green complex in Szczecin on the east side of the Odra river.
The study was performed using methods described by the British Aerobiology Federation (1995): each weekly tape was cut into seven pieces-each corresponding to 1 day of the weekly sampling. Afterwards these were stained (with a solution of fuchsine, gelatine, glycerol and phenol) and mounted on microscope slides with cover slips and stored in special cases. Daily records of airborne fungal spores were obtained by means of counting all spores in one longitudinal traverse per microscope slide at $\times 400$. After counting the spores in each sampling area, a specific correction factor for the microscope used was applied. Thus, the final counts of fungal spores were expressed as average daily number of spores per cubic metre of air.

The meteorological data covering the 4 years of studies were provided by the Automatic Weather Station (Vaisala MAWS101 Finland). The meteorological station was located in the immediate neighbourhood of the Lanzoni trap. The meteorological parameters considered were: daily level of precipitation, maximum wind speed, average wind speed, relative humidity, maximum, minimum and average air temperature, dewpoint temperature. The daily values of these parameters were taken as arithmetic means. Due to similar correlations between Ganoderma sp.-original meteorological factors and Ganoderma sp.-meteorological factors with lags, only the original variables were introduced into the data set.

The spore data was analysed in order to determine the start, end and duration of the season using the $90 \%$ method. The start of the season was defined as the date when $5 \%$ of the seasonal cumulative spore count was trapped, and the end of the season as the date when $95 \%$ of the seasonal cumulative spore count was reached (British Aerobiology Federation 1995).

\section{Data analysis}

The spore seasons were relatively short and null values prevailed in the Ganoderma sp. spore concentration (Fig. 1).

As shown in Fig. 2, the Ganoderma sp. spore data approximated an exponential distribution. In turn, meteorological parameters mostly approximated a normal distribution; however, the Shapiro-Wilk test confirmed significant deviations from normality (results not shown). The scatter plots indicated non-linear dependencies between Ganoderma sp. spore concentration and meteorological parameters.

Due to non-linearity and non-normality, neither the Pearson's correlation coefficient nor multiple regression could have been used. Therefore, the Spearman's rank correlation, ANN and MRT models were applied in order to examine the studied relationships. Meteorological parameters were used as input variables while Ganoderma sp. spore concentration was the output variable. 


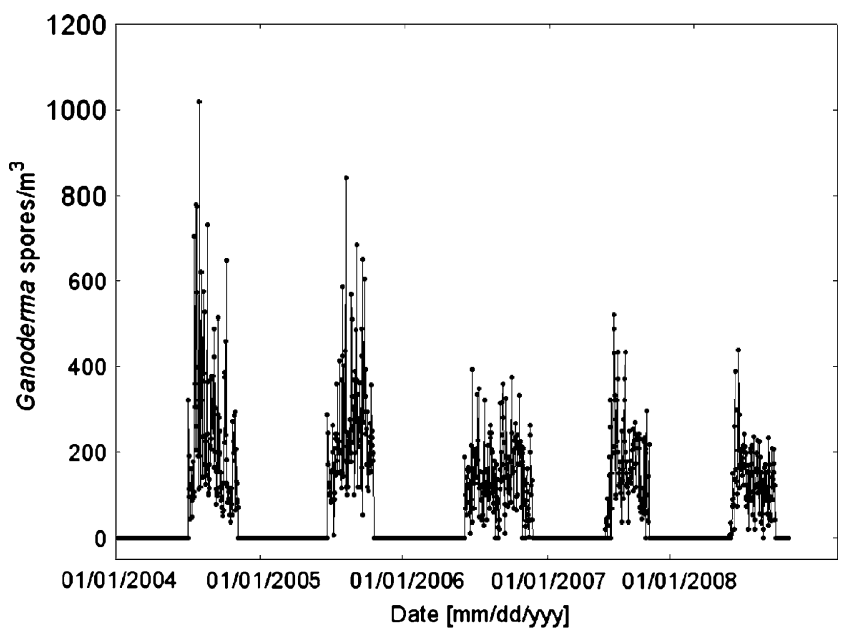

Fig. 1 Ganoderma sp. spore concentration in the years 2004-2008 (Szczecin, Poland)

From a statistical point of view, relatively high Ganoderma sp. concentrations during spore seasons comparing to long periods of spore absence, as well as rapid appearance of spores at the beginning of spore seasons, suggested that there were some threshold meteorological conditions above which Ganoderma sp. occurred. In order to reveal the cut-off values of the environmental predictors we used the MRT method
(Breiman et al. 1984; De'ath and Fabricus 2000) and ANN model classification (Fausett 1994; Tadeusiewicz 2001).

MRT analysis was performed on the original data set. This method makes no assumptions about the form of the relationships (e.g. unimodal or linear) between species and their environmental predictors. Moreover, this method can be applied to complex ecological data with imbalance, nonlinear relationships between variables and high-order interactions (De'ath and Fabricus 2000). MRT models species-environment relationships and forms clusters by repeated splitting of the data, with each split chosen to minimise the dissimilarity (sum of squared Euclidian distances, SSD) within clusters (Breiman et al. 1984; De'ath and Fabricus 2000). The overall fit of a tree is specified as relative error (RE; SSD in clusters divided by SSD of undivided data), while the predictive accuracy is assessed by cross-validated relative error (CVRE; Breiman et al. 1984; De'ath and Fabricus 2000). In this study, the finally selected tree was the model with minimum CVRE, according to De'ath and Fabricus (2000), using 1,000 multiple cross validations to stabilise the cross-validated error. MRT analyses were carried out in R 2.1.1 using the mvpart (Multivariate Partitioning) package.

For ANN models, multi layer perceptrons (MLP) were applied to classify the presence (1) and absence (0) of

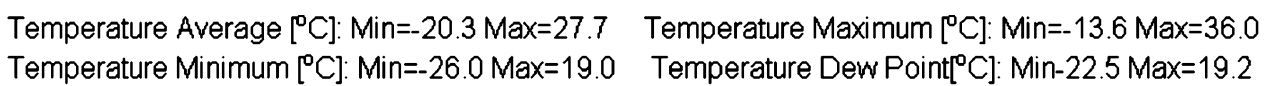
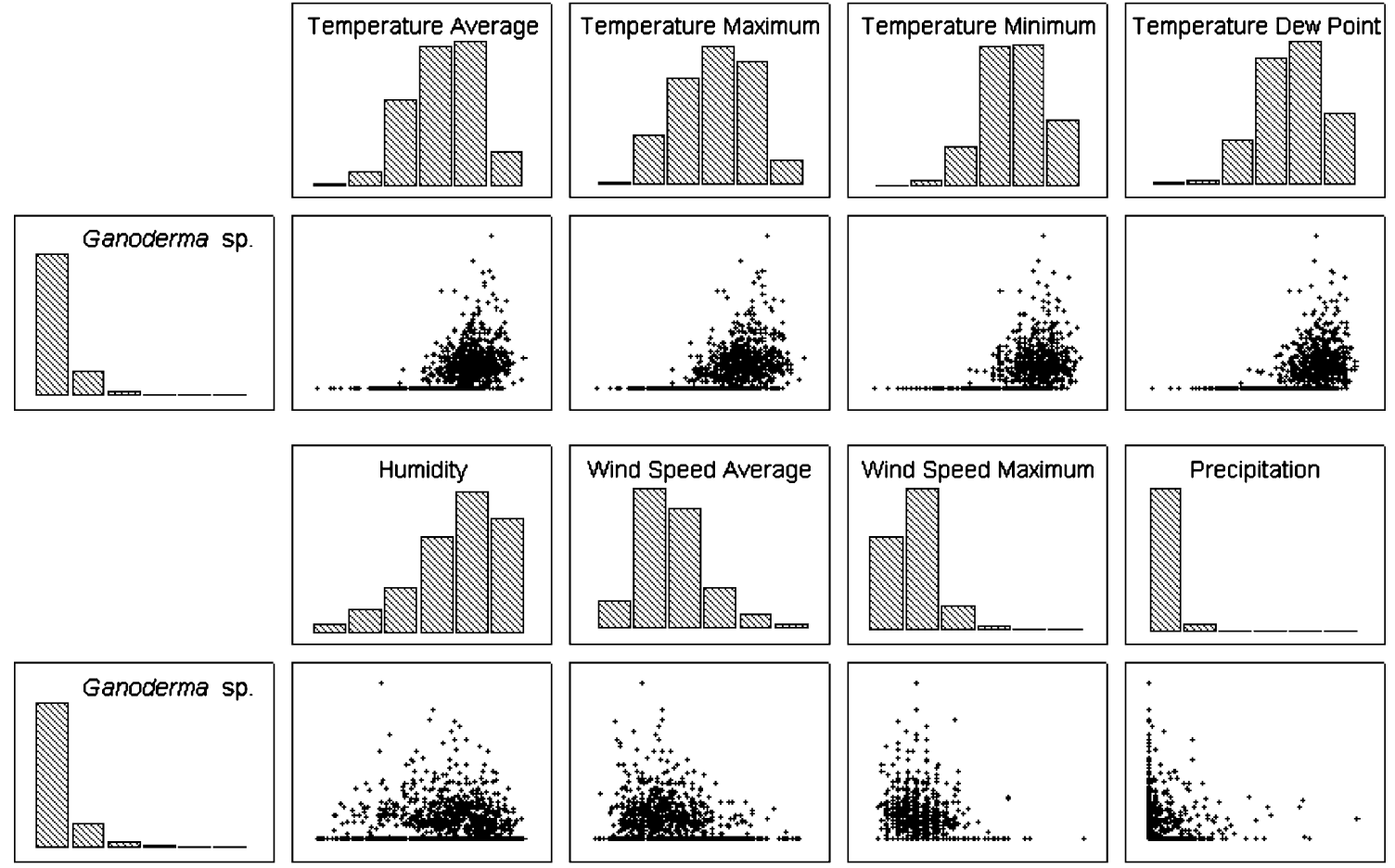

Humidity [\%]: Min=36.0 Max=100.0 Wind Speed Average [m/s]: Min=0.1 Max=8.8

Wind Speed Maximum [m/s]: Min=1.9 Max=22.7 Precipitation [mm]: Min=0.0 Max=45.9

Fig. 2 Matrix scatter plots between Ganoderma sp. spore concentration and meteorological factors (whole data set, raw data) 


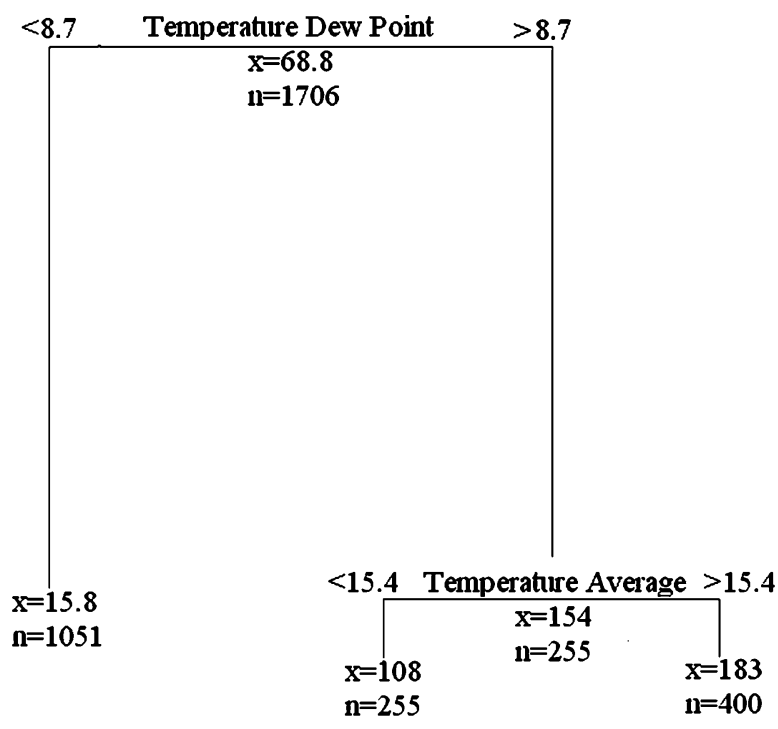

Relative Error: 0.64 Cross-Validated Relative Error: 0.67 SE: 0.06

Fig. 3 Multivariate regression tree (MRT) of the relationships between Ganoderma sp. spores and meteorological factors. $x$ Average spore concentration, $n$ number of cases

Ganoderma sp. with meteorological factors. The consecutive neural networks were designed and trained using back propagation (Haykin 1994; Fausett 1994; Patterson 1996) and conjugate gradient algorithms (Bishop 1995) by Automatic Problem Solver. Cases were divided into three subsets: using the bootstrap method

- training (Tr) — used for training a neural network;

- verification (Ve) - used for verifying performance of a network during training;

- testing (Te) - used for assessing predictability and accuracy of a neural model on data not presented during training and validation (cases remained after creating a training subset during bootstrap).

The choice criterion of the best neural network analysed was the percentage of correctly classified cases. Special emphasis was placed on sensitivity analysis and response plots. Sensitivity analysis creates ranking of input variables and is based on calculations of the error when a given input variable is removed from the model. The ratio of the error for the complete model to the one with ignored variable is the basis of ordering variables according to their importance. The response plot is the model response (output) as the function of one selected input variable, assuming constant values of other variables, or in other words, a one-dimensional section through the response surface in the $\mathrm{N}$-dimensional space of input variables.

ANN models were used for regression analysis of spore seasons in order to examine the relationships between meteorological parameters and Ganoderma sp. spore concentration. The methodology was similar to that in the classification analysis but the choice criteria of the best neural network were: value of SD ratio (ratio between error standard deviation and standard deviation of experimental data) and correlation (Pearson's correlation coefficient between experimental and calculated data).

\section{Results}

\section{Classification models}

In the MRT model obtained (Fig. 3), the most important factor was the dew point temperature, with a threshold value equal to $8.7^{\circ} \mathrm{C}$. Below this temperature, the average Ganoderma sp. spore concentration was 15.8 spores $/ \mathrm{m}^{3}$ (1,051 cases), while above $8.7^{\circ} \mathrm{C}$ the spore concentration was $154 \mathrm{spores} / \mathrm{m}^{3}$ (255 cases). That first split actually defined absence and presence of Ganoderma sp. in the air. At higher dew point temperatures, another meteorological factor - average temperature-revealed its importance. A dew point temperature higher than $8.7^{\circ} \mathrm{C}$ and average temperature above $15.4^{\circ} \mathrm{C}$ favoured higher average concentrations of Ganoderma sp. spores (183 spores $/ \mathrm{m}^{3}, 183$ cases), comparing to 108 spores $/ \mathrm{m}^{3}$ at average temperature $<15.4^{\circ} \mathrm{C}$ (255 cases).

The best classification ANN model was MLP 8:8-11-1:1 with 8 input neurons, 11 hidden neurons and 1 output neuron. The percentage of correctly classified cases was $92.5 \%$ for absence (0) and $70.9 \%$ for presence (1) of Ganoderma sp. spores. Sensitivity analysis (Table 1) showed that the most important factors were humidity and dew point temperature, with ratio equal to 1.01 .

An interesting response plot was obtained for dew point temperature. Below around $11^{\circ} \mathrm{C}$ the model predicted the absence of Ganoderma sp. spores, while above that threshold, the presence of Ganoderma sp. spores was predicted (Fig. 4).

Table 1 Sensitivity analysis for MLP 8:8-11-1:1 classification neural model

\begin{tabular}{lllllll}
\hline & $\begin{array}{l}\text { Average } \\
\text { temperature }\end{array}$ & $\begin{array}{l}\text { Maximum } \\
\text { temperature }\end{array}$ & $\begin{array}{l}\text { Minimum } \\
\text { temperature }\end{array}$ & $\begin{array}{c}\text { Dew point } \\
\text { temperature }\end{array}$ & $\begin{array}{l}\text { Relative } \\
\text { humidity }\end{array}$ & $\begin{array}{c}\text { Average } \\
\text { wind speed } \\
\text { wind speed } \\
\text { Ratio }\end{array}$ \\
0.96 & 0.97 & 0.94 & 1.01 & 1.01 & 1.00 \\
Rank & 7 & 6 & 8 & 2 & 1 & 3 \\
\hline
\end{tabular}




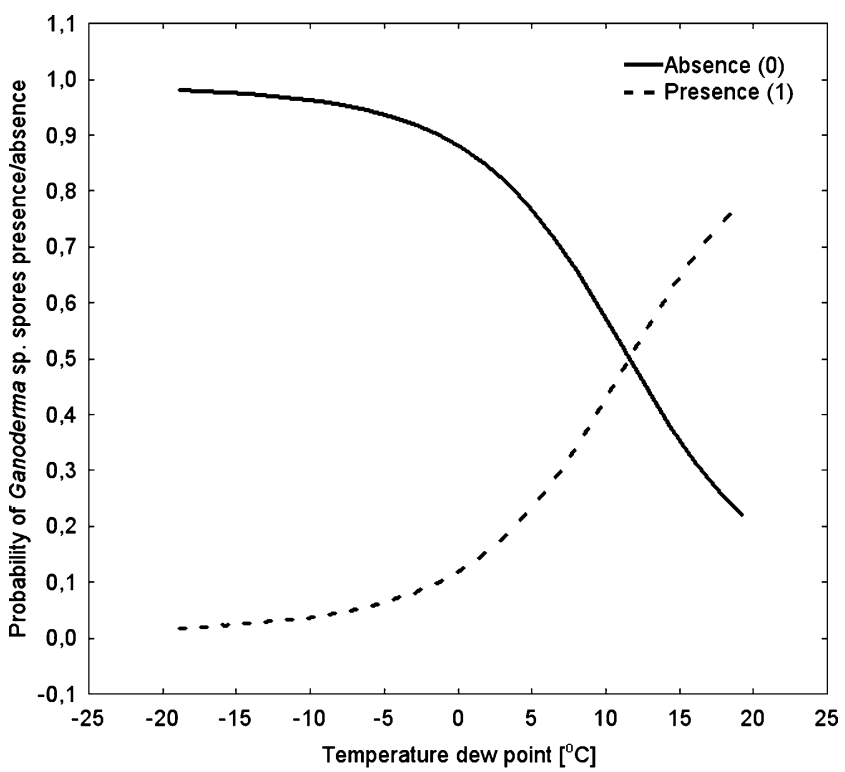

Fig. 4 Response plot for Ganoderma sp. spore concentration in dependence on dew point temperature from the multi layer perceptrons (MLP) 8:8-11-1:1 classification neural model

\section{Regression model for spore seasons}

The performance of the ANN regression model for spores seasons was very low both for original and $\log (\mathrm{x}+1)$ transformed Ganoderma sp. spore concentration. Usually such transformation dampens the effect of rapid changes in variable values, but in this case the Pearson's correlation coefficient between experimental and predicted data was still below 0.4 , while SD ratio was above 0.8 . Such a low network performance resulted in poor predictive abilities of the model and therefore was not analysed further.

Spearman's rank correlation analysis also revealed the weak influence of meteorological parameters on Ganoderma sp. spore concentration (Table 2). For maximum temperature, average temperature and dew point temperature, the coefficients were positive, significant for $P=0.001$ and ranged from 0.141 to 0.192 . Low negative correlation were observed in the case of humidity $(P=0.001)$, precipitation $(P=0.001)$ and average wind speed $(P=0.05)$; coefficients ranged from -0.078 to -0.155 . There were no significant correlations between Ganoderma sp. spore concentration and minimum temperature or maximum wind speed.

\section{Discussion}

Ganoderma sp. spores were present in the atmosphere on $90 \%$ of the days from June to October of 2004-2008. The results were comparable to those obtained in other parts of the world. Oliveira et al. (2005) reported from Portugal that maximum Ganoderma sp. spore release occurred during late summer and autumn. The same results were obtained in Melbourne, Australia (Mitakakis and Guest 2001); and in Kerala, India (Jothish and Nayar 2004). Despite the consistent occurrence of spores throughout the 5 years studied, seasonal levels of Ganoderma sp. spores were highly variable.

The presence of high concentrations of Ganoderma sp. basidiospores may be important for understanding allergic reactions. Aerobiological investigations should contribute to the understanding of allergic manifestations caused by basidiospores of Ganoderma sp. Therefore, there is increasing interest in the development of statistical models of high predictive power for atmospheric levels of airborne fungal spores that will allow allergic individuals to take preventative action. For this, we undertook this first study of the occurrence of Ganoderma sp. spores depending on particular weather parameters in Poland.

MRT analysis revealed that the presence or absence of Ganoderma sp. spores depends mostly on dew point temperature, with a threshold value of around $9^{\circ} \mathrm{C}$. Similar results were obtained in neural network modelling. The sensitivity analysis of ANN model classification showed that the most important factors determining Ganoderma sp. presence/absence were dew point temperature and humidity, with a cut-off value for the former variable of about $11^{\circ} \mathrm{C}$. Less important but still significant were maximum and average wind speed and precipitation. No other authors have noted the correlation between dew point temperature and Ganoderma sp. concentrations but a significant, positive relationship with relative humidity, studied using multiple regression, was reported in Poland (Stępalska and Wołek 2005; Grinn-Gofroń 2008).

Table 2 Spearman's rank correlation coefficients between meteorological parameters and Ganoderma spore concentration in spore seasons

\begin{tabular}{llllllll}
\hline & $\begin{array}{l}\text { Average } \\
\text { temperature }\end{array}$ & $\begin{array}{l}\text { Maximum } \\
\text { temperature }\end{array}$ & $\begin{array}{l}\text { Minimum } \\
\text { temperature }\end{array}$ & $\begin{array}{c}\text { Dew point } \\
\text { temperature }\end{array}$ & $\begin{array}{l}\text { Relative } \\
\text { humidity }\end{array}$ & $\begin{array}{l}\text { Average } \\
\text { wind } \\
\text { speed }\end{array}$ & $\begin{array}{l}\text { Maximum } \\
\text { wind speed }\end{array}$ \\
\hline $\begin{array}{l}\text { Spearman's rank } \\
\text { correlation } \\
\text { coefficient }\end{array}$ & $0.167 * * *$ & $0.192 * * *$ & 0.070 & $0.141^{* * *}$ & $-0.142 * * *$ & $-0.078^{*}$ & -0.074 \\
\hline
\end{tabular}

$* P<0.05, * * P<0.01, * * * P<0.001$ 
Calderon et al. (1995), in Mexico City, observed the largest concentrations of basidiospores when relative humidity was $70-80 \%$. It is well known that high humidity and rain favour the production and liberation of basidiospores. This compares with the reports of McCracken (1987) and Hasnain et al. (2004) that humidity levels of about $70 \%$ are associated with increased concentrations of Ganoderma sp. spores.

Hasnain (1993) in Auckland and Craig and Levetin (2000) in Tulsa noted a significant correlation with precipitation. Ganoderma sp. is considered as a wet-air spore because its concentrations showed marked seasonal differences, with the highest numbers during the wet season, and water is important factor involved in spore release. Lacey (1990) observed an abundance of basidiospores during the rainy period in tropical countries. The rainy season accelerates development of sporocarps and the release of more spores because of high humidity and water availability.

The actual mechanism of ballistospore discharge in the Basidiomycetes is not clear (Inglod 1976). Fungi exhibiting a forcible mechanism of discharge probably use an interaction between a gas-bubble mechanism and an electrostatic mechanism (Saville 1965). If a typical gilled Hymenomycete can absorb adequate moisture from rain, it likely can maintain a stable micro-climate inside the basidiocarp to enhance spore release and dispersal regardless of the humidity level surrounding the basidiocarp. Spore release would continue until the moisture available in the basidiocarp and outlying mycelium was used up.

Hasnain (1993) and Calderon et al. (1995) reported that high concentrations of basidiospores were often associated with daily average wind speeds of $2-3 \mathrm{~m} \mathrm{~s}^{-1}$. Lopez and Salvaggio (1983) observed that wind velocities $>5 \mathrm{~m} \mathrm{~s}^{-1}$ were correlated with decreased spore concentrations, perhaps because of the diluting effect of high wind speeds on the concentrations of airborne particles. In addition, increasing wind speed would also increase water loss and may, in turn, suppress spore production.

Spearman's rank correlation analysis for spore seasons revealed that maximum average and dew point temperature were most strongly and directly proportional to the concentration of analysed fungal spores. Similar correlations with maximum and average temperature were noted by Hasnain (1993) in New Zealand. Positive, significant correlation between Ganoderma sp. spore concentration and average temperature was reported from Tulsa in Oklahoma (Craig and Levetin 2000) and from Porto, Portugal (Oliveira et al. 2005).

The very low performance of regression models for seasons suggests that there are other variables influencing Ganoderma sp. spore concentration that are more important than meteorological factors.
In conclusion, this study showed that (1) the season for airborne Ganoderma sp. spores lasts from June through October in Szczecin; (2) the dew point temperature was the most important predictor for presence/absence of Ganoderma sp. spores during the whole year as measured by ANN and MRT; (3) Spearman's rank correlations were significant but rather weak between the spore concentration during spore seasons and maximum, average and dew point temperatures as well as humidity, average wind speed and precipitation. Additional data collected annually could provide a more accurate determination of variations in spore concentration over time.

Open Access This article is distributed under the terms of the Creative Commons Attribution Noncommercial License which permits any noncommercial use, distribution, and reproduction in any medium, provided the original author(s) and source are credited.

\section{References}

Bishop C (1995) Neural networks for pattern recognition. University Press, Oxford

British Aerobiology Federation (1995) Airborne pollens and spores. A guide to trapping and counting, 1st edn. National Pollen and Hayfever Bureau, Rotherham

Breiman L, Friedma JH, Olshen RA, Stone CG (1984) Classification and regression trees. Wadsworth International Group, Belmont

Butcher BT, O'Neal CE, Reed MA, Altman LC, Lopez M, Lehrer SB (1987) Basidiomycete allergy: measurement of spore specific IgE antibodies. J Allergy Clin Immunol 80:803-809

Calderon C, Lacey J, McCartney HA, Rosas I (1995) Seasonal and diurnal variation of airborne basidiomycete spore concentrations in Mexico City. Grana 34:260-268

Craig RL, Levetin E (2000) Multi-year study of Ganoderma aerobiology. Aerobiologia 16:75-80

De'ath G, Fabricus KE (2000) Classification and regression trees: a powerful and simple technique for ecological data analysis. Ecology 81:3178-3192

Fausett L (1994) Fundamentals of Neural Networks. Prentice Hall, New York

Gregory PH, Hirst JM (1952) Possible role of basidiospores as airborne allergens. Nature 170:414

Grinn-Gofron A (2008) The variation in spore concentrations of selected fungal taxa associated with weather conditions in Szczecin, Poland, 2004-2006. Grana 47:139-146

Halwagy MH (1994) Fungal airspora of Kuwait city, Kuwait. Grana 33:340-345

Hasnain SM (1993) Influence of meteorological factors on the airspora. Grana 32:184-188

Hasnain SM, Al-Frayth A, Khatija F, Al-Sedairy S (2004) Airborne Ganoderma basidiospores in a country with desert environment. Grana 43:111-115

Hawksworth DL, Sutton BC, Ainsworth G (1983) Dictionary of the fungi, 7th edn. Commonwealth Mycological Institute, Kew

Haykin S (1994) Neural networks: a comprehensive foundation. Macmillan, New York 
Inglod CT (1976) Fungal spores: their liberation and dispersal. Clarendon, Oxford

Jothish PS, Nayar TS (2004) Airborne fungal spores in a sawmill environment in Palakkad District, Kerala, India. Aerobiologia 20:75-81

Lacey J (1990) Aerobiology and health: the role of airborne fungal spores in respiratory allergy diseases. In: Hawksworth DL (ed) Frontiers in Mycology. CBA, Wallingford, pp 131-156

Lopez M, Salvaggio EJ (1983) Climate-Weather-Air Pollution. In: Middleton E, Reed CE, Ellis EF (eds) Allergy: principle and practice, 2nd edn. Mosby, St. Louis, pp 1203-1214

Lehrer SB, Hughes JM, Altman LC, Bousquet J, Davies RJ, Gell Li J, Lopez M, Malling HJ, Mathison DA, Sastre J, SchultzeWerninghaus G, Schwartz HJ (1994) Prevalence of basidiomycete allergy in the USA and Europe and its relatuionship to allergic respiratory symptoms. Allergy 49:460-465

Levetin E (1990) Studies on airborne basidiospores. Aerobiologia 6:177-180

Levetin E (1991) Identification and concentration of airborne basidiospores. Grana 30:123-128

Li DW, Kendrick B (1994) Functional relationships between airborne fungal spores and environmental factors in Kitchener-Waterloo, Ontario, as detected by canonical correspondence analysis. Grana 33:166-176
Li DW, Kendrick B (1995) A year-round outdoor aeromycological study in Waterloo, Ontario, Canada. Grana 34:199-207

McCracken FL (1987) Factors affecting the spore release of Ganoderma applanatus. J MI Acad Sci 32:55-60

Mitakakis TZ, Guest DI (2001) A fungal spore calendar for the atmosphere of Melbourne, Australia, for the year 1993. Aerobiologia 17:171-176

Oliveira M, Ribeiro H, Abreu I (2005) Annual variation of fungal spores in atmosphere of Porto: 2003. Ann Agric Environ Med 12:309-315

Patterson D (1996) Artificial neural networks. Prentice Hall, Singapore

Saville DBO (1965) Spore discharge in Basidiomycetes: a unified theory. Science 147:165-166

Singh AB, Gupta SK, Pereira BMJ, Prakash D (1995) Sensitization to Ganoderma lucidum in patients with respiratory allergy in India. Clin Exp Allergy 25:440-447

Stępalska D, Wołek J (2005) Variation in fungal spore concentrations of selected taxa associated to weather conditions in Cracow, Poland, in 1997. Aerobiologia 21:43-52

Tarlo SM, Bell B, Srinivasan DJ, Hargreave FE (1979) Human sensitization to Ganoderma antigen. J Allergy Clin Immunol 64:43-49

Tadeusiewicz R (2001) Introduction to artificial neural networks (in Polish). Kraków, Statsoft Polska 